Research Paper

\title{
Heat Transfer Enhancement for site level indirect heat recovery systems using nanofluids as the intermediate fluid
}

\author{
Amir H. Tarighaleslami*, Timothy G. Walmsley, Martin J. Atkins, Michael R.W. Walmsley, James R. Neale \\ Energy Research Centre, School of Engineering, University of Waikato, Private Bag 3105, Hamilton 3240, New Zealand
}

H I G H L I G H T S

- Using a nanofluid as an intermediate fluid for Heat Recovery Loops (HRL) was studied.

- The nanofluid provides passive Heat Transfer Enhancement for HRL heat exchangers.

- CuO/water (1.5 vol.\%) nanofluid was modelled in a Heat Recovery Loop system.

- Liquid-liquid heat exchangers experienced a 5-9\% increase in duty due to nanofluid.

\section{A R T I C L E I N F O}

\section{Article history:}

Received 2 January 2016

Revised 8 March 2016

Accepted 24 March 2016

Available online $\mathrm{xxxx}$

\section{Keywords:}

Nanoparticle

Nanofluid

Intermediate fluid

Process Integration

Heat Recovery Loop

Heat Transfer Enhancement

\begin{abstract}
A B S T R A C T
In this paper, implementation of nanofluids as a Heat Transfer Enhancement technique in Process Integration has been studied. A step by step flowchart is introduced and as a case study the effect of replacing water with various nanofluids as the heat transfer media in an industrial Heat Recovery Loop (HRL) has been modelled. Nanofluids are prepared by distributing a nanoparticle through a base fluid such as water, ethylene glycol or oils. Suspended nanoparticles slightly affect the thermal and physical properties of the base fluid. Primarily nanoparticles are added to improve the fluid's heat transfer characteristics by increasing its Reynolds number and thermal conductivity. HRL system in a large dairy factory in New Zealand has been studied as case study. Results show that by applying various HRL design methods and a nanofluid as an intermediate fluid, an increase in heat recovery is possible without the need for extra heat exchanger area and infrastructure. $1.5 \mathrm{vol}$ \% $\mathrm{CuO} /$ water nanofluid has been chosen as an intermediate fluid and by using a constant temperature storage control strategy, heat recovery from liquid-liquid heat exchangers increases between $5 \%$ and $9 \%$. The air-side heat transfer coefficient limits the impact of using a nanofluid for the air-liquid exchangers. In other cases, the total available duty from the process stream, such as a condenser, significantly nullifies the heat transfer benefit of using a nanofluid in a retrofit situation. Alternative to increasing heat recovery, results show that applying a nanofluid in the HRL design phase enables heat exchanger area to decrease significantly for liquid-liquid matches. Results show that the increase in pressure drop and friction factor effects in such a system is negligible.
\end{abstract}

(c) 2016 Elsevier Ltd. All rights reserved.

\section{Introduction}

Intense competition to gain more share in markets and high energy prices motivate industries to apply energy saving methods as much as possible in their plants. Process Integration (PI) techniques have been commonly applied in a wide variety of industries to realise meaningful increases in energy efficiency through improved intra- and inter-process and plant integration [1]. Different concepts and methods have been proposed to minimise energy use in process plants ranging from heat recovery systems for

\footnotetext{
* Corresponding author.

E-mail address: aht5@students.waikato.ac.nz (A.H. Tarighaleslami).
}

individual processes to Total Site Heat Integration. In individual processes, various techniques have been applied to increase heat transfer rates in heat exchangers. These methods are known as Heat Transfer Enhancement (HTE). Generally speaking, HTE techniques are divided in two main groups: active techniques and passive techniques. In active techniques, an external force is required, such as surface vibration, electrical or magnetic field, or acoustic move on fluid. Passive techniques, on the other hand, require no external forces. Rather, passive techniques increase heat transfer by changing the surface geometry or by adding some additives to the fluids [2]. Active techniques due to their additional energy requirement are less often considered in PI methods, while passive technique are common in PI literature. 


\section{Nomenclature}

$C_{p} \quad$ specific heat $\left(\mathrm{J} / \mathrm{kg}{ }^{\circ} \mathrm{C}\right)$

$\mathrm{CP} \quad$ heat capacity flow rate $\left(\mathrm{kW} /{ }^{\circ} \mathrm{C}\right)$

$f$ friction factor

$h \quad$ convective heat transfer coefficient $\left(\mathrm{kW} / \mathrm{m}^{2}{ }^{\circ} \mathrm{C}\right)$

HTC convective heat transfer coefficient $\left(\mathrm{kW} / \mathrm{m}^{2}{ }^{\circ} \mathrm{C}\right)$

$K \quad$ thermal conductivity $\left(\mathrm{W} / \mathrm{m}{ }^{\circ} \mathrm{C}\right)$

$\mathrm{NF}$ nanofluid

$\mathrm{Nu} \quad$ Nusselt number

$P \quad$ pressure $(\mathrm{Pa})$

Pe Peclet number

$\mathrm{Pr} \quad$ Prandtl number

Re Reynolds number

$T$ temperature $\left({ }^{\circ} \mathrm{C}\right)$

$U \quad$ overall heat transfer coefficient $\left(\mathrm{kW} / \mathrm{m}^{2}{ }^{\circ} \mathrm{C}\right)$

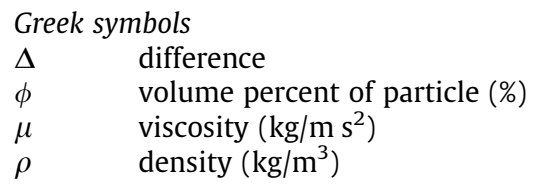

\section{Subscripts}

bf base fluid

min minimum

nf nanofluid

np nanoparticle

s supply

$\mathrm{t}$ target
HTE procedure for Heat Exchangers Network (HEN) retrofit has been suggested by Zhu et al. [3]. His method is based on accounting for HTE effects in the application of Pinch Analysis techniques. Pan et al. [4] performed HTE tests for commercial shell and tube heat exchangers using turbulators for intensified tube side heat transfer. Optimisation of large scale HEN with different intensified heat transfer is their latest HTE study in PI area [5]. These techniques, such as inserting turbulators in tubes and using helical baffles in shells [6], are useful for shell and tube heat exchangers, which are a common heat exchanger type in chemical process industries. However, other techniques are presented for HTE of other heat exchanger types such as CFD analysis in plate-fin heat exchangers [7].

For many decades, adding solid micron-sized particles to conventional fluids for HTE has been considered due to their high thermal conductivity. However, in practice, operational problems, such as fouling, sedimentation and increased pressure drop, occur by using these additives which dissuades industry from applying this type of HTE technique. Recent progress in nanomaterials technology has made it conceivable to overcome these problems by producing particles at a nano-scale. Compared to micron-sized particles, nanoparticles are engineered to have larger relative surface area, high mobility, less particle momentum and higher suspension stability. Suspended nanoparticles in a fluid creates a new category of fluids called nanofluids. Nanofluids are a class of fluids with a suspension of nano-sized particles, which aims to enhance a fluid's heat and mass transfer performance [8]. Water, ethylene glycol, transformer and turbine oil, and liquid paraffin are usually used as the base fluid, while metals and metal oxides, such as $\mathrm{Cu}, \mathrm{CuO}, \mathrm{Al}_{2} \mathrm{O}_{3}, \mathrm{SiO}_{2}, \mathrm{TiO}_{2}$, as well as non-metallic particles, such as Multiwall Carbon Nanotubes. The size of the nanoparticles are typically $<100 \mathrm{~nm}$.

Peyghambarzadeh et al. [9] showed that using a nanofluid can increase the heat transfer coefficient, $h$, of car radiators by up to $40 \%$. Later they showed the overall heat transfer coefficient, $U$, increased with the application of dilute nanofluids in the car radiator [10]. This research group demonstrated that using 0.4 vol.\% $\mathrm{CuO} /$ water nanofluid can increase the overall heat transfer coefficient by up to $8 \%$ in car radiators [11]. Wu et al. [12] presented the thermal performance of MWCNT/water nanofluids in helical heat exchangers. Tohidi et al. [13] showed the combination of chaotic advection and nanofluids flow in helically coiled tubes offers higher heat transfer coefficient. Pantzali et al. [14] studied the efficiency of $\mathrm{CuO} /$ water nanofluid with 4 vol.\% of $\mathrm{CuO}$ nanoparticles as coolants in commercial plate heat exchangers. Tabari and
Heris [15] studied heat transfer coefficient of milk pasteurization plate heat exchanger using MWCNT/water nanofluid, and recently, the effect of hybrid MWCNT/water and $\mathrm{Al}_{2} \mathrm{O}_{3}$ /water nanofluid mixture in plate heat exchangers has been studied by Huang et al. [16]. Each of these studies was at the laboratory scale, meaning the implementation of nanofluids in large scale industrial applications is not reported yet. Furthermore, the application of nanofluids, in combination with an integrated process's utility system has not been investigated.

Along with other principles of Process Integration techniques, Pinch Analysis has been established as one of the most useful tools for analysing and optimising energy systems of process plants. These standard techniques can be applied for targeting energy use and developing heat exchanger networks for single plants [17]. On a wider scale, Total Site Integration offers energy conservation opportunities for sites with multiple processes and plants. Dhole and Linnhoff [18] introduced the Total Site concept to describe a set of processes serviced by and linked through a central utility system. By considering inter-plant integration, Total Site Analysis has the potential to identify further energy savings. By using an intermediate fluid such as steam or hot oil (for high temperature processes) or hot water (for low temperature processes) through a central utility system, indirect integration offers greater advantages of flexibility and process control but has a lower energy recovery target compared to direct integration.

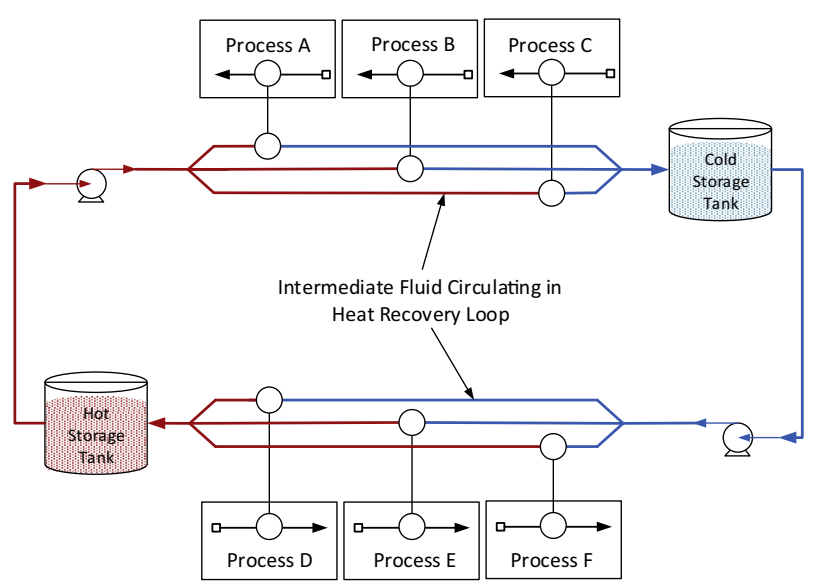

Fig. 1. A schematic of conventional Heat Recovery Loop. 
There is opportunity to use a nanofluid as the intermediate fluid for a site's hot water recovery and utility systems as a means of HTE. In this case, the intermediate fluid transfers excess heat from one plant to another, passing through a network of heat exchangers. Thermal storage is needed to balance the instantaneous imbalances of the intermediate fluid flow between distinct processes. Such a system is sometimes called a Heat Recovery Loop (HRL) [19]. Fig. 1 shows a schematic of a HRL system. In recent years, several researchers have studied various parts of the design, operation and optimisation of HRLs, e.g. new thermal storage design by using a stratified tank [20], changing of storage temperature for seasonal production changes [19], utilisation and sizing of thermal storage capacity [21], area targeting and storage temperature selection for HRL [22]. Further, Walmsley et al. [23] have explained the evaluation of heat exchanger sizing methods for improving the area and storage temperature selection in HRLs. Recently, Chang et al. presented the use of MINLP model with economic objectives to optimise hot water circles [24] and HRLs [25].

In this paper, the benefits of using a nanofluid in a large scale industrial plant is investigated. A step by step procedure for choosing nanoparticles, base fluid, thermo-physical properties and heat transfer correlations is proposed to show how to find the appropriate nanofluid to implement into an existing HRL in a process plant. Various combinations of nanoparticles in water (base fluid) are examined to find which combination returns the best heat coefficient for the same vol.\% of nanoparticles added. The selected nanofluid is then modelled as the intermediate fluid in an industrial HRL model.

\section{Methods}

\subsection{Nanofluid selection procedure and considerations}

In this section, a systematic method for nanofluid selection and its implementation in process industries is presented. These methods are developed for low temperature (i.e. below $120^{\circ} \mathrm{C}$ ) processes that are suitable for implementation of nanofluids as the heat transfer media in their utility system. Low temperature processes are normally non-continuous and are operate at lower total heat loads. The method for nanofluid selection for implementing in an industrial system is explained in Fig. 2.

The first decision is back to the nature of the process and the nanoparticles that are going to be added to the base fluid. For instance, if the process is a pharmaceutical or food and dairy processing, application of some type of nanoparticles might not be allowed. Therefore, technical documents such as MSDS might be useful in this stage. In any fluid heat transfer system, the effect of heat transfer is described by the convective heat transfer coefficient of the fluids, which is a function of a number of thermo-physical properties; the most significant ones are thermal conductivity, density, viscosity and specific heat. Several experimental correlations are proposed in literature for nanofluids [2]. In order to match the best one to the system, a designer should consider the geometry of process and heat transfer equipment that the nanofluid will pass through. Following thermo-physical property correlation selection and calculations, appropriate correlations for heat transfer coefficients and pressure drop should be selected for the process. Different heat transfer equipment such as heat exchangers, cooling towers, furnaces etc. might be a constraint in the process. Next step is calculation of the amount of nanoparticles in nanofluid. To do this, plotting the volume fraction of particles $(\phi)$ versus various number of parameters such as convective heat transfer coefficient, Reynolds number, Nusselt number, friction factor, and pressure drop may give a good insight to the designer for selecting the best nanoparticle/nanofluid and its concentration for

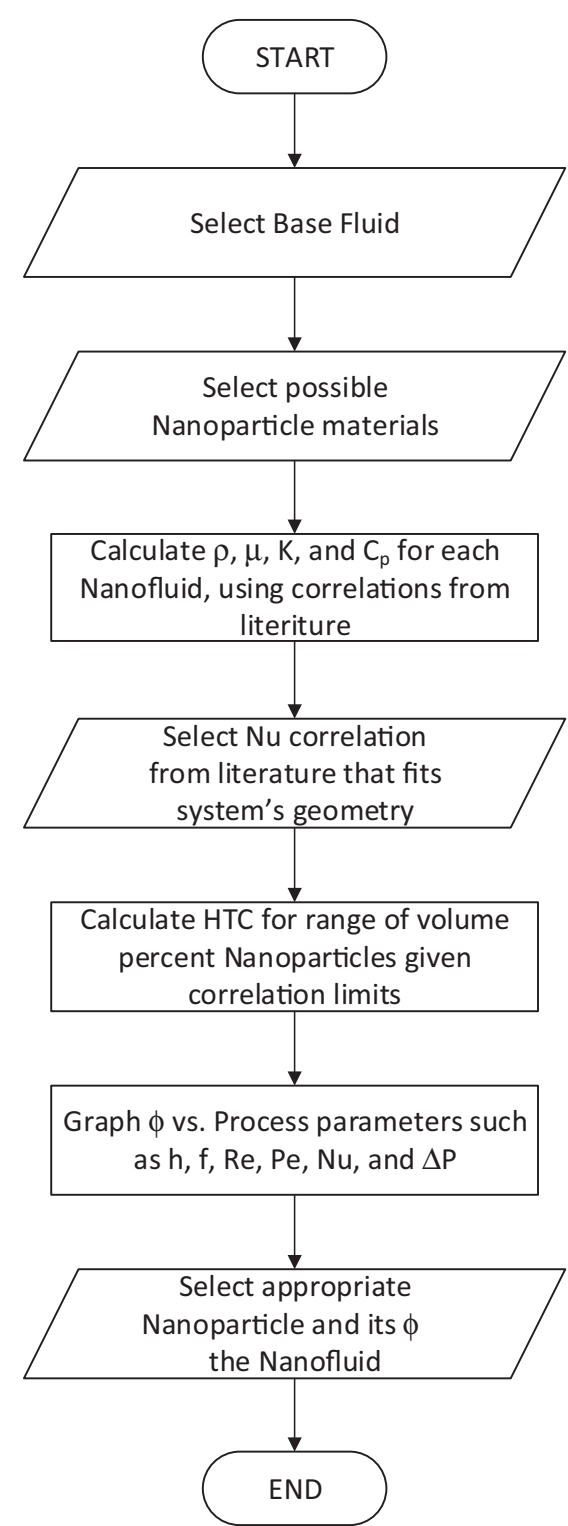

Fig. 2. Nanofluid selection procedure for an industrial application.

the system. Increased convective heat transfer coefficient on one side of the heat exchanger that is matched to the HRL system will affect overall heat transfer coefficient. This increase will show significant impact on heat transfer and duty for individual heat exchangers and, consequently, heat recovery of the whole system.

\subsection{Heat Recovery Loop methodology for Total Site Heat Integration}

Intermediate fluid in HRLs, which normally is non-isothermal, assists the process to transfer heat from one plant to another. The conventional control system of a HRL measures and compares the outlet temperature of the loop fluid from each heat exchanger to a common hot or cold temperature set point. The flow rate of fluid through each heat exchanger is adjusted to achieve set point temperature. In this approach hot and cold storage temperatures are constant over time, thus this approach is called the Constant Temperature Storage (CTS) approach. Walmsley et al. [26] introduced an alternative approach to HRL control which is varying the set point of the heat exchangers depending on their temperature driving force. This alternative approach is called Variable Temperature Storage (VTS) due to mixing of different temperatures 
entering the tanks. Recently, Walmsley et al. [27] have compared the two HRL control approaches to find the VTS system results in more effective distribution of temperature driving force between heat exchangers, lower average loop flow rates giving reduced pressure drop and pumping requirements, and increase in average temperature difference of hot and cold storage temperature, which increases thermal storage density and capacity and continued by Walmsley et al. [28].

The steady state minimum temperature difference $\left(\Delta T_{\min }\right) \mathrm{HRL}$ design [23], is applied for transient stream data analysis to calculate heat recovery. Four methods to operate and design a HRL have been applied based on methodologies presented by Walmsley et al. [29] for the current case study, these are:

1. Conventional design method with CTS control.

2. VTS method of HRL design and operation.

3. CTS method using selected nanofluid as intermediate fluid in HRL.

4. VTS method using the same selected nanofluid as intermediate fluid in HRL.

Walmsley et al. [29] show that VTS method provides more heat recovery than CTS method. In this paper, based on the existing methods, the percent increase in heat recovery for the two HRL design methods using nanofluid as heat transfer media are compared to see if the one benefits more than the other.

\section{Modelling of nanofluids in an industrial heat recovery case study}

A large multi-plant dairy factory, which is located in New Zealand, has been chosen as a case study. The factory consists of eight separate semi-continuous processes that share common utility, power and materials handling services. Plants have been previously investigated and integrated to industry best practice. A HRL was installed as a dedicated indirect heat recovery system to increase inter-plant heat integration. The existing HRL is using water as the intermediate fluid. Further improvements in HRL performance using HTE are desired. Modifying intermediate fluid (water) to become a nanofluid is therefore investigated.

\subsection{Data extraction}

In this section, process stream data extraction and nanofluid basic data (i.e. nanoparticle and base fluid) extraction is presented.

Table 1

Extracted process stream data from dairy factory.

\begin{tabular}{lllll}
\hline Stream & Type & $T_{s}\left({ }^{\circ} \mathrm{C}\right)$ & $T_{t}\left({ }^{\circ} \mathrm{C}\right)$ & $\mathrm{CP}\left(\mathrm{kW} /{ }^{\circ} \mathrm{C}\right)$ \\
\hline Dryer Exhaust A & Hot & 75 & 55 & 139 \\
Dryer Exhaust B & Hot & 75 & 55 & 73 \\
Dryer Exhaust C & Hot & 75 & 55 & 44 \\
Dryer Exhaust D & Hot & 75 & 55 & 28 \\
Utility Unit A & Hot & 45 & 30 & 8 \\
Utility Unit B & Hot & 45 & 30 & 8 \\
Casein A & Hot & 50 & 20 & 22 \\
Casein B & Hot & 50 & 20 & 32 \\
Casein C & Hot & 50 & 20 & 32 \\
Condenser & Hot & 80 & 79 & 351 \\
Cheese A & Hot & 35 & 20 & 98 \\
Cheese B & Hot & 35 & 20 & 114 \\
Site Hot Water & Cold & 16 & 65 & 160 \\
Milk Treatment A & Cold & 10 & 50 & 104 \\
Milk Treatment B & Cold & 10 & 50 & 104 \\
Milk Treatment C & Cold & 11 & 50 & 116 \\
Whey A & Cold & 12 & 45 & 16 \\
Whey B & Cold & 14 & 45 & 9
\end{tabular}

\subsubsection{Process streams data extraction}

Process streams from each individual semi-continuous plant connected to the HRL are presented in Table 1 , where $T_{s}$ and $T_{t}$ are supply and target temperatures, and $\mathrm{CP}$ represents timeaverage heat capacity flow rate. The data is taken from Walmsley et al. [26] where the full transient characteristics of the various streams are presented.

\subsubsection{Nanoparticle and base fluid data extraction}

The intermediate fluid which is used in existing HRL is water, as explained before; therefore, water has been chosen as base fluid due to its availability in the system, high heat capacity, nontoxicity and cheap price. A range of nanoparticles have been considered to be investigated to find the one that best match's the system. Table 2 presents the thermo-physical properties of the base fluid and nanoparticle which are used in this research.

\subsection{Nanofluid thermo-physical property estimation}

The effective thermo-physical properties of the nanofluid can be estimated using classical correlations as usually used for two phase fluid mixtures. For these correlations, nanoparticles are assumed well dispersed within the base fluid and the concentration of the nanoparticles are considered uniform in the system.

Plate Heat Exchangers (PHE) are the most common exchangers in dairy factories. To calculate thermo-physical properties of the nanofluid given the geometry of the system, the following correlations have been chosen for density Eq. (1), dynamic viscosity Eq. (2), thermal conductivity Eq. (3), and heat capacity Eq. (4), which were used by Khairul et al. [30].

$\rho_{\mathrm{nf}}=(1-\phi) \rho_{\mathrm{bf}}+\phi \rho_{\mathrm{np}}$

$\mu_{\mathrm{nf}}=(1+2.5 \phi) \mu_{\mathrm{bf}}$

$K_{\mathrm{nf}}=(3.761088 \phi+0.017924 T+0.69266) K_{\mathrm{bf}}$

$c_{\mathrm{p}, \mathrm{nf}}=\frac{(1-\phi)\left(\rho c_{\mathrm{p}}\right)_{\mathrm{bf}}+\phi\left(\rho c_{\mathrm{p}}\right)_{\mathrm{np}}}{\rho_{\mathrm{nf}}}$

\subsection{Nanofluid convective heat transfer coefficient correlation selection}

Considering the system's geometry, i.e. type of heat exchangers, flow regime, hydraulic of system, etc., the most suitable correlation should be selected [31]. Several experimental and theoretical studies on the convective heat transfer coefficient of nanofluids in PHEs under a turbulent regime have been reported in literature. Khairul et al. [30] illustrated that the heat transfer coefficient of $\mathrm{CuO} /$ water nanofluid increased by $18-27 \%$ compared to water. Their work was very similar to a previous study of the same nanofluid, which presented the following Nusselt number correlation [32].

$N u=\left(0.26+0.02 \phi-0.0051 \phi^{2}\right) P e^{0.27} \quad 0.5 \leqslant \phi \leqslant 1.5$

Tiwari et al. [33] investigated nanofluids made by using $\mathrm{Al}_{2} \mathrm{O}_{3}$, $\mathrm{SiO}_{2}, \mathrm{TiO}_{2}$ and $\mathrm{CeO}_{2}$ nanoparticles. Their investigation showed the heat transfer coefficient of the nanofluid increased with

Table 2

Thermo-physical properties of nanoparticles and water (base fluid) at $25^{\circ} \mathrm{C}$.

\begin{tabular}{lcccl}
\hline Nanoparticle/fluid & $\rho\left(\mathrm{kg} / \mathrm{m}^{3}\right)$ & $K\left(\mathrm{~W} / \mathrm{m}^{\circ} \mathrm{C}\right)$ & $C_{p}\left(\mathrm{~J} / \mathrm{kg}{ }^{\circ} \mathrm{C}\right)$ & $\mu\left(\mathrm{kg} / \mathrm{m} \mathrm{s}^{2}\right)$ \\
\hline $\mathrm{CuO}$ & 6500.0 & 20.0 & 535.6 & - \\
$\mathrm{Al}_{2} \mathrm{O}_{3}$ & 3600.0 & 36.0 & 765.0 & - \\
$\mathrm{SiO}_{2}$ & 2200.0 & 1.4 & 745.0 & - \\
$\mathrm{Cu}$ & 8933.0 & 401.0 & 385.0 & - \\
Water & 988.2 & 0.6 & 4182.0 & 0.001
\end{tabular}


increases in the volume flow rate of the non-nanofluid and nanofluid and with a decrease in the main fluid temperature. They summarised their results using Eq. (6).

$$
N u=0.348 \operatorname{Re}^{0.663} \operatorname{Pr}^{0.33} \quad 0.5 \leqslant \phi \leqslant 3.0
$$

Pantzali et al. [14] developed Eq. (7) as they studied the efficiency of $\mathrm{CuO} /$ water nanofluid with 4 vol.\% of $\mathrm{CuO}$ nanoparticles as coolants in commercial PHE. According to their findings, the nature of coolant flow, e.g. turbulent flow, inside the heat exchanger play a significant role in the effectiveness of nanofluids.

$N u=0.247 \operatorname{Re}^{0.66} \operatorname{Pr}^{0.4} \quad \phi \leqslant 4.0$

\subsection{Nanofluid selection and heat transfer coefficient calculation}

$\mathrm{CuO} /$ water, $\mathrm{Al}_{2} \mathrm{O}_{3} /$ water, $\mathrm{SiO}_{2} /$ water and $\mathrm{Cu} /$ water nanofluids have been initially investigated to find the best nanofluid for use in a HRL system. An Excel ${ }^{\mathrm{TM}}$ spreadsheet has been developed in order to calculate thermo-physical properties of nanofluids including their heat transfer coefficient using Eqs. (5)-(7). To validate developed spreadsheet, Nusselt No. vs. Peclet No. has been plotted in Fig. 3.

Fig. 3 is plotted for more point by using similar geometrical and process conditions for lab scale PHE and nanofluid, which has been presented by Khairul et al. [30], which is compatible with similar graph in their work. To choose appropriate nanofluid, several options of nanofluid and their impact on the heat transfer coefficient have been plotted in Fig. 4, by using Eqs. (1)-(4).

Fig. 4 shows $\mathrm{Cu} /$ water nanofluids tend to obtain the highest increases in convective heat transfer coefficient. However, at nano scale it is likely that $\mathrm{Cu}$ particles will oxidize in the vicinity of water. Therefore, for our purpose $\mathrm{CuO} /$ water nanofluid, the second best, has been chosen. The most important part of analysing nanofluid Heat Transfer Enhancement is to find how much different correlations led to increase in heat transfer coefficient when compared to water. Since Eqs. (4)-(7) are based on experiments with different geometries and process characterizations (i.e. different heat exchanger size and flow rate), calculated convective heat transfer coefficients using mentioned correlations are not is same order of magnitude. Therefore, a unified measure as per cent increase in convective heat transfer coefficient has been calculated to compare these set of equations.

Fig. 5 illustrates that according to Eq. (5) percentage change in heat transfer coefficient increase up to $25 \%$ at 1.5 vol.\% in the nanofluid, while Eqs. (6) and (7) show a linear increase by increasing of nanoparticle volume percentage in the nanofluid. Thus, achieving the same increase in heat transfer coefficient for Eqs. (6) and (7) needs more nanoparticles in nanofluid which may cause higher capital costs and operating cost due to increase in pressure drop. Therefore, as it is shown in Fig. 5, Eq. (5) has presented highest

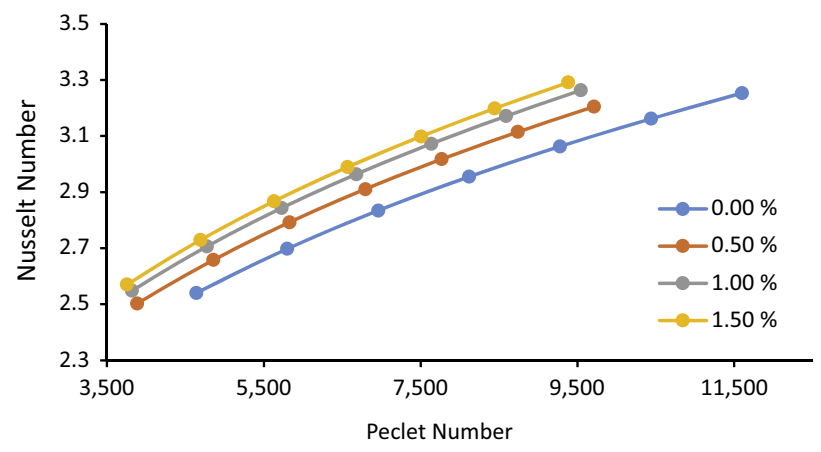

Fig. 3. Calculated $\mathrm{Nu}$ vs. Pe graph for Khairul et al. [30] experimental data.

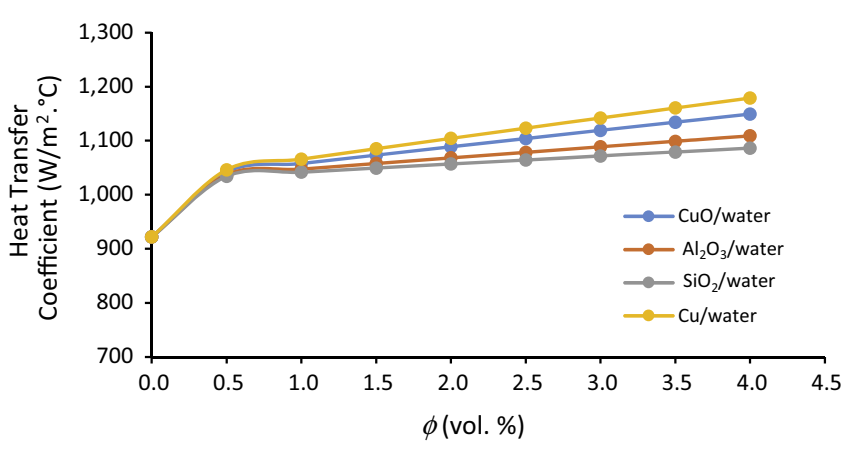

Fig. 4. Heat transfer coefficient vs. volumetric percentage of $\mathrm{CuO} /$ water, $\mathrm{Al}_{2} \mathrm{O}_{3} /$ water, $\mathrm{SiO}_{2} /$ water and $\mathrm{Cu} /$ water nanofluids.

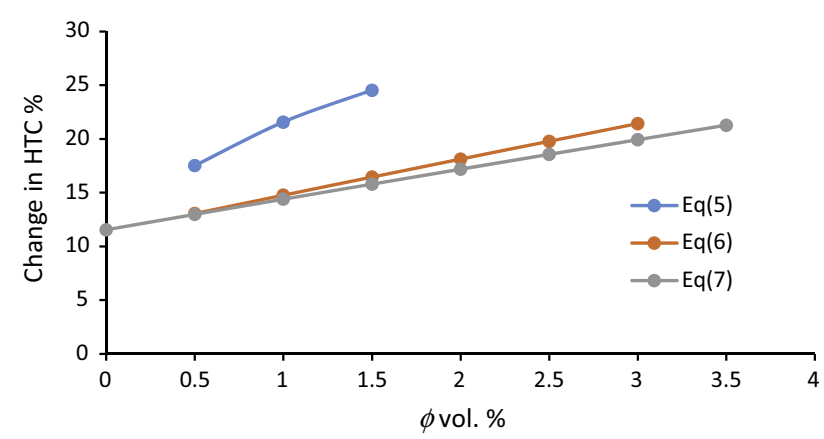

Fig. 5. Comparison of heat transfer coefficient increase percentage vs. volumetric percentage of $\mathrm{CuO} /$ water nanofluid for Eqs. (5)-(7).

increase in heat transfer coefficient in its maximum nanoparticle volume fraction range which is in middle range for Eqs. (6) and (7). All above led to select $\mathrm{CuO} /$ water nanofluid with 1.5 vol.\% of nanoparticle to observe $25 \%$ increase in HRL intermediate fluid convective heat transfer coefficient.

Table 3 shows the comparison between thermo-physical properties of the water, as base fluid, and $\mathrm{CuO} /$ water, as nanofluid, in HRL. An increase in density, thermal conductivity and viscosity values for the nanofluid as well as decrease in heat capacity is as expected. Adding $1.5 \mathrm{vol} . \% \mathrm{CuO} /$ water nanofluid is estimated to increase the heat transfer coefficient by $25 \%$ (Eq. (5)), from $4.00 \mathrm{~kW} / \mathrm{m}^{2}{ }^{\circ} \mathrm{C}$ to $5.00 \mathrm{~kW} / \mathrm{m}^{2}{ }^{\circ} \mathrm{C}$.

\section{Results and discussion}

Major process parameters may affect by replacing current intermediate fluid by selected nanofluid (i.e. CuO/water in this case) are investigated to illustrate the advantages and/or disadvantages of such a replacement in existing HRL of the case study.

\subsection{Heat recovery potential}

The increase of heat recovery as result of applying each design and control procedure is presented in Fig. 6. Adding nanofluid to

Table 3

Comparison between thermo-physical properties of base fluid and nanofluid in HRL.

\begin{tabular}{llllll}
\hline Fluid & $\begin{array}{l}\rho \\
\left(\mathrm{kg} / \mathrm{m}^{3}\right)\end{array}$ & $\begin{array}{l}C_{p} \\
\left(\mathrm{~J} / \mathrm{kg}{ }^{\circ} \mathrm{C}\right)\end{array}$ & $\begin{array}{l}K \\
\left(\mathrm{~W} / \mathrm{m}{ }^{\circ} \mathrm{C}\right)\end{array}$ & $\begin{array}{l}\mu \\
\left(\mathrm{kg} / \mathrm{m} \mathrm{s}^{2}\right)\end{array}$ & $\begin{array}{l}h \\
\left(\mathrm{~kW} / \mathrm{m}^{2}{ }^{\circ} \mathrm{C}\right)\end{array}$ \\
\hline Water & 1000.0 & 4182.0 & 0.6000 & 0.00100 & 4.00 \\
CuO/water & 1080.7 & 3853.0 & 0.7382 & 0.00104 & 5.00 \\
\hline
\end{tabular}




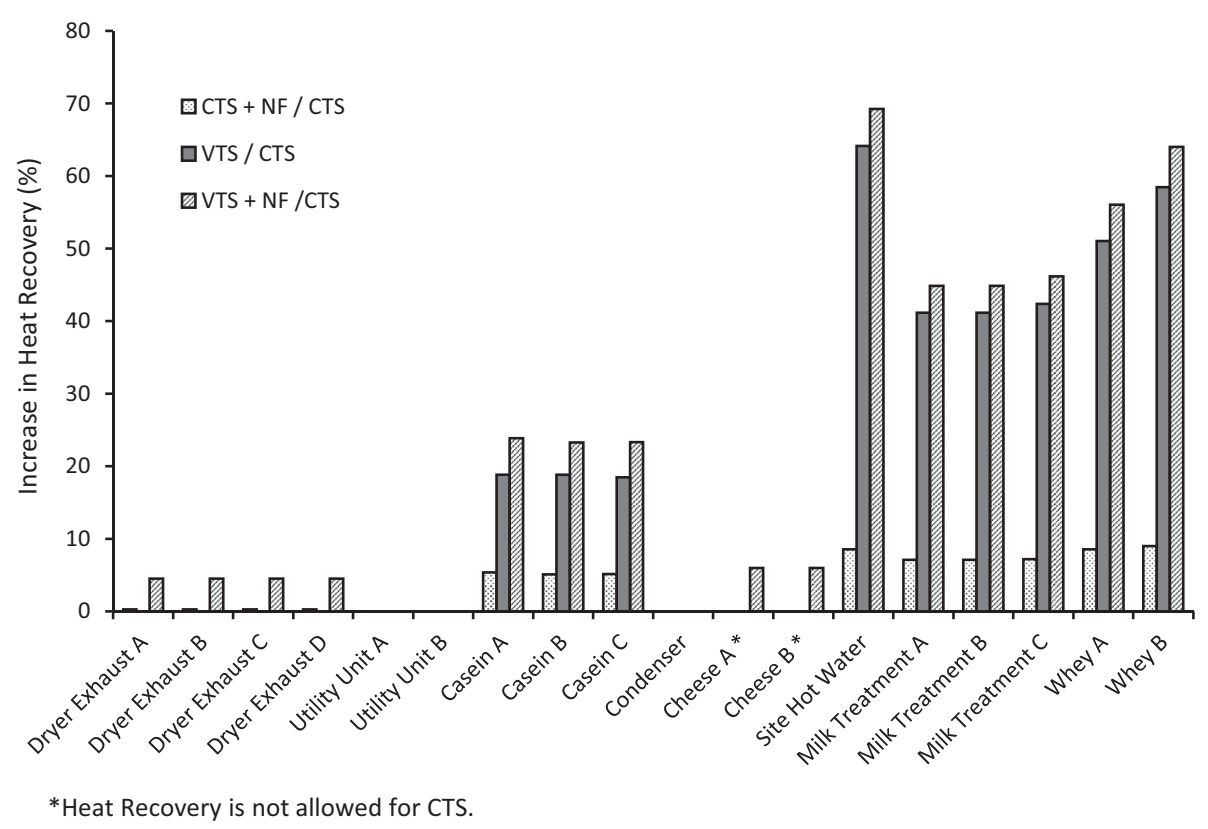

Fig. 6. Heat recovery increase in each process heat exchanger, comparison between four different methods.

the original intermediate fluid, i.e. water, in both methods show an increase in average heat recovery.

In the CTS method with nanofluid comparing to CTS method without nanofluid, a wide range of variation in increased heat recovery for the process streams on the HRL. The highest increase is in Whey B with 9\% increase and lowest increase is shown in Casein plants, especially Casein B with $5.1 \%$ increase. For hot streams Cheese $\mathrm{A}^{*}$ and $\mathrm{B}^{*}$, in case of the CTS method, the hot loop temperature is greater than the stream's supply temperature, and therefore heat recovery is not allowed under the CTS approach. For Dryer Exhaust A, B, C, and D a very small increase is observed, which indicates the air side is the limiting heat transfer coefficient. Also, Utility A and B and Condenser have fixed duties and so increasing the heat transfer coefficient does not impact on heat recovery.

In case of CTS and VTS methods, a significant increase in VTS heat recovery is illustrated in Fig. 6. This increase is due to the more constraint which is considered in VTS method. Site Hot Water shows the highest increase in heat recovery with $65 \%$ and Whey $B$ and $A$ have second and third high increase with $58 \%$ and $51 \%$, respectively. Dryer Exhausts have no change due to same conditions in both methods.

In the case of applying VTS and VTS with nanofluid methods, again a wide range of differences in increase of heat recovery appears. In this case, Cheese $\mathrm{A}$ shows highest heat recovery increase with $6 \%$ while Milk Treatment A and B have the lowest increase, $2.6 \%$. Moreover, it shows a small change in heat recovery for Dryer Exhaust A, B, C, and D and again hot utilities which are condenser, Utility A, and Utility B remain constant due to their fixed duty. Average increase of heat recovery for the entire factory is about $4 \%$ in the case of CTS with nanofluids and $2.5 \%$ in the case of VTS with nanofluids. Liquid-liquid heat exchangers, exclusively,

Table 4

Comparison of reduction in heat transfer area for different matches.

\begin{tabular}{lc}
\hline Match type & Estimated reduction in area (\%) \\
\hline Gas-liquid & 0.3 \\
Vapour-liquid & 7.5 \\
Liquid-liquid & 10.0 \\
\hline
\end{tabular}

shows $7 \%$ and $4 \%$ increase respectively for CTS and VTS with nanofluids. The differences in the increases in heat recovery between the streams are due to different stream characteristics, flow rates, and heat exchanger types and geometries.

\subsection{Heat transfer area}

If a nanofluid and its enhanced heat transfer coefficient were applied in the design process to obtain the same duties as the original design without nanofluids, total heat transfer area decreases as given in Table 4. Liquid-Liquid matches show a decrease in area of $10 \%$ whereas the decrease in area for gas-liquid matches is negligible as the gas side plays the controlling role in overall heat transfer coefficient of the heat exchanger. Table 5 indicates the match type for each individual stream. It can be seen that most of the processes have Liquid-Liquid match. Therefore, average 10\% reduction in capital investment for the heat recovery system and site can be considered.

\subsection{Pressure drop and friction factor}

Eq. (8) presents the empirical correlation for friction factor, using experimental data [32] for water and nanofluid in a lab scale PHE.

$f=\left(2.9+5.6 \phi-0.12 \phi^{2}\right) P e^{-0.13}$

$\mathrm{CuO} /$ water nanofluid with different particle volume fractions is employed in the friction factor computation. Fig. 7 illustrates by the lab scale PHE data [32], friction factor increased with the increase of nanoparticle concentration in nanofluid. However, it decreases for higher coolant flow rate as $5 \mathrm{~L} / \mathrm{min}$ nanofluid has lower friction factor than $2 \mathrm{~L} / \mathrm{min}$ in any concentration of nanofluid.

Pressure drop is a function of number of parameters such as friction factor, density, viscosity, volumetric flow rate and in addition the geometry of the heat exchanger. In higher amount of flow rates which is used in our industrial case study, the effect of nanoparticles concentration on friction factor is neglected. Therefore, using nanofluid as intermediate fluid in HRL has negligible effect on pressure drop as well as pumping power. 
Table 5

Different match types for processes in the case study dairy factory.

\begin{tabular}{llll}
\hline Stream & \multicolumn{2}{l}{ Match type } & \\
\cline { 2 - 3 } & Gas-liquid & Vapour-liquid & Liquid-liquid \\
\hline Dryer Exhaust A & $\mathrm{X}$ & \\
Dryer Exhaust B & $\mathrm{X}$ & \\
Dryer Exhaust C & $\mathrm{X}$ & \\
Dryer Exhaust D & $\mathrm{X}$ & $\mathrm{X}$ \\
Utility Unit A & & $\mathrm{X}$ \\
Utility Unit B & & $\mathrm{X}$ \\
Casein A & & $\mathrm{X}$ \\
Casein B & & $\mathrm{X}$ \\
Casein C & & \\
Condenser & & $\mathrm{X}$ \\
Cheese A & & $\mathrm{X}$ \\
Cheese B & & $\mathrm{X}$ \\
Site Hot Water & & $\mathrm{X}$ \\
Milk Treatment A & & $\mathrm{X}$ \\
Milk Treatment B & & $\mathrm{X}$ \\
Milk Treatment C & & $\mathrm{X}$ \\
Whey A & $\mathrm{X}$ \\
Whey B & &
\end{tabular}

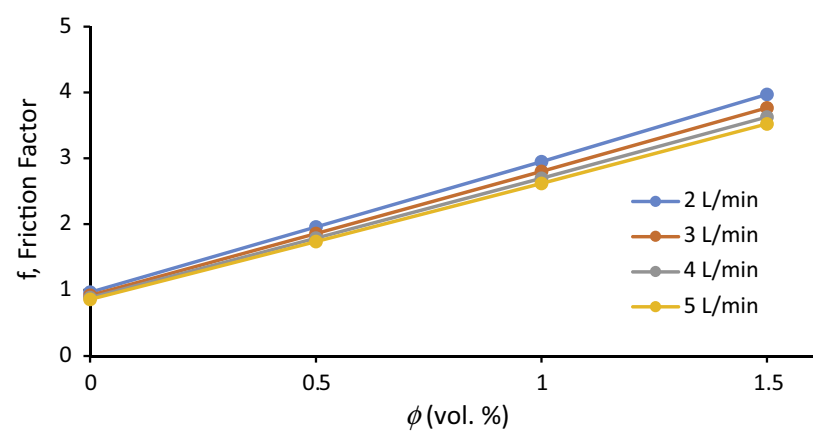

Fig. 7. Comparison of $\phi$ vs. $f$ (friction factor) for $\mathrm{CuO} /$ water nanofluid in different flow rates in a PHE, data from [32].

Current work is initial steps to this new concept of increasing Process Integration through nanofluid Heat Transfer Enhancement techniques. For example, other base fluids such as ethylene glycol, if there are no compatibility constraints for its use with the process, may be considered. Hybrid nanofluids [16] that achieve higher heat transfer rates may also be studied. Further experimental investigations for determining the thermal and hydraulic performance of nanofluids using a broader range of heat exchanger geometries, operating conditions and volume percent of nanoparticles in nanofluids.

\section{Conclusions}

Step by step procedure for implementation of Heat Transfer Enhancement technique in Process Integration methods has been presented. Adding $1.5 \mathrm{vol} \% \mathrm{CuO}$ to the intermediate fluid of a HRL shows an increase in heat recovery of whole plant. Results show that by applying various HRL design methods accompanied by using nanofluid as an intermediate fluid is desirable way of achieving significant heat recovery without the need for extra heat exchanger area and infrastructure. In the case of air-liquid exchangers, it is clear that the air side heat transfer coefficient plays a significant role in controlling the overall heat transfer coefficient and in utility and condenser streams no changes in heat recovery are observed because they are a fixed duty. Alternative to increasing heat recovery, results show that by using nanofluid as intermediate fluid of HRL total heat exchanger area in the HRL for liquid-liquid heat exchangers decreases significantly. Increase in pressure drop and friction factor caused by nanofluid in comparison by base fluid in HRL system can be neglected due to the hydraulic of the system and high flow rates.

\section{References}

[1] J.J. Klemeš, Handbook of Process Integration: Minimisation of Energy and Water Use, Waste and Emissions, Woodhead Publishing, Cambridge, UK, 2013.

[2] G. Huminic, A. Huminic, Application of nanofluids in heat exchangers: a review, Renew. Sustain. Energy Rev. 16 (8) (2012) 5625-5638.

[3] X.X. Zhu, M. Zanfir, J. Klemeš, Heat transfer enhancement for heat exchanger network retrofit, Heat Transf. Eng. 21 (2) (2000) 7-18.

[4] M. Pan, I. Bulatov, R. Smith, J.-K. Kim, Novel optimization method for retrofitting heat exchanger networks with intensified heat transfer, in: M.C. Georgiadis, A.C. Kokossis, E.N. Pistikopoulos (Eds.), Computer Aided Chemical Engineering, vol. 29, Elsevier, 2011, pp. 1864-1868.

[5] M. Pan, I. Bulatov, R. Smith, Exploiting tube inserts to intensify heat transfer for the retrofit of heat exchanger networks considering fouling mitigation, Ind. Eng. Chem. Res. 52 (8) (2013) 2925-2943.

[6] M.R. Jafari Nasr, A. Shafeghat, Fluid flow analysis and extension of rapid design algorithm for helical baffle heat exchangers, Appl. Therm. Eng. 28 (11-12) (2008) 1324-1332.

[7] M. Khoshvaght-Aliabadi, F. Hormozi, A. Zamzamian, Effects of geometrical parameters on performance of plate-fin heat exchanger: Vortex-generator as core surface and nanofluid as working media, Appl. Therm. Eng. 70 (1) (2014) 565-579.

[8] W. Daungthongsuk, S. Wongwises, A critical review of convective heat transfer of nanofluids, Renew. Sustain. Energy Rev. 11 (5) (2007) 797-817.

[9] S.M. Peyghambarzadeh, S.H. Hashemabadi, S.M. Hoseini, M. Seifi Jamnani, Experimental study of heat transfer enhancement using water/ethylene glycol based nanofluids as a new coolant for car radiators, Int. Commun. Heat Mass Transf. 38 (9) (2011) 1283-1290.

[10] S.M. Peyghambarzadeh, S.H. Hashemabadi, M. Naraki, Y. Vermahmoudi, Experimental study of overall heat transfer coefficient in the application of dilute nanofluids in the car radiator, Appl. Therm. Eng. 52 (1) (2013) 8-16.

[11] M. Naraki, S.M. Peyghambarzadeh, S.H. Hashemabadi, Y. Vermahmoudi, Parametric study of overall heat transfer coefficient of $\mathrm{CuO} /$ water nanofluids in a car radiator, Int. J. Therm. Sci. 66 (2013) 82-90.

[12] Z. Wu, L. Wang, B. Sundén, L. Wadsö, Aqueous carbon nanotube nanofluids and their thermal performance in a helical heat exchanger, Appl. Therm. Eng. 96 (2016) 364-371.

[13] A. Tohidi, H. Ghaffari, H. Nasibi, A.S. Mujumdar, Heat transfer enhancement by combination of chaotic advection and nanofluids flow in helically coiled tube, Appl. Therm. Eng. 86 (2015) 91-105.

[14] M.N. Pantzali, A.A. Mouza, S.V. Paras, Investigating the efficacy of nanofluids as coolants in plate heat exchangers (PHE), Chem. Eng. Sci. 64 (14) (2009) 3290 3300.

[15] Z.T. Tabari, S.Z. Heris, Heat transfer performance of milk pasteurization plate heat exchangers using MWCNT/water nanofluid, J. Dispers. Sci. Technol. 36 (2) (2015) 196-204.

[16] D. Huang, Z. Wu, B. Sunden, Effects of hybrid nanofluid mixture in plate heat exchangers, Exp. Therm. Fluid Sci. 72 (2016) 190-196.

[17] I.C. Kemp, Pinch Analysis and Process Integration, second ed., ButterworthHeinmann, Cambridge, UK, 2007.

[18] V.R. Dhole, B. Linnhoff, Total site targets for fuel, co-generation, emissions, and cooling, Comput. Chem. Eng. 17 (Suppl. 1) (1993) S101-S109.

[19] M.J. Atkins, M.R.W. Walmsley, J.R. Neale, The challenge of integrating noncontinuous processes - milk powder plant case study, J. Clean. Prod. 18 (9) (2010) 927-934

[20] M.R.W. Walmsley, M.J. Atkins, J. Riley, Thermocline management of stratified tanks for heat storage, Chem. Eng. Trans. 18 (2009) 231-236.

[21] M.J. Atkins, M.R.W. Walmsley, J.R. Neale, Process integration between individual plants at a large dairy factory by the application of heat recovery loops and transient stream analysis, J. Clean. Prod. 34 (2012) 21-28.

[22] M.R.W. Walmsley, T.G. Walmsley, M.J. Atkins, J.R. Neale, Area targeting and storage temperature selection for heat recovery loops, Chem. Eng. Trans. 29 (2012) 1219-1224.

[23] M.R.W. Walmsley, T.G. Walmsley, M.J. Atkins, J.R. Neale, Methods for improving heat exchanger area distribution and storage temperature selection in heat recovery loops, Energy 55 (2013) 15-22.

[24] C. Chang, Y. Wang, X. Feng, Indirect heat integration across plants using hot water circles, Chin. J. Chem. Eng. 23 (6) (2015) 992-997.

[25] C. Chang, Y. Wang, X. Feng, P. Zhang, Efficient solution strategy for stage-wise MINLP model of interplant heat integration using heat recovery loop, Chem. Eng. Trans. 45 (2015) 67-72.

[26] T.G. Walmsley, M.R.W. Walmsley, A.H. Tarighaleslami, M.J. Atkins, J.R. Neale, Integration options for solar thermal with low temperature industrial heat recovery loops, Energy 90 (Part 1) (2015) 113-121.

[27] M.R.W. Walmsley, T.G. Walmsley, M.J. Atkins, J.R. Neale, Options for solar thermal and heat recovery loop hybrid system design, Chem. Eng. Trans. 39 (2014) 361-363. 
[28] T.G. Walmsley, M.R.W. Walmsley, M.J. Atkins, J.R. Neale, Integration of industrial solar and gaseous waste heat into heat recovery loops using constant and variable temperature storage, Energy 75 (2014) 53-67.

[29] M.R.W. Walmsley, T.G. Walmsley, M.J. Atkins, J.R. Neale, Integration of solar heating into heat recovery loops using constant and variable temperature storage, Chem. Eng. Trans. 35 (2013) 1183-1188.

[30] M.A. Khairul, M.A. Alim, I.M. Mahbubul, R. Saidur, A. Hepbasli, A. Hossain, Heat transfer performance and exergy analyses of a corrugated plate heat exchanger using metal oxide nanofluids, Int. Commun. Heat Mass Transf. 50 (2014) 8-14.
[31] V. Kumar, A.K. Tiwari, S.K. Ghosh, Application of nanofluids in plate heat exchanger: a review, Energy Convers. Manag. 105 (2015) 1017-1036.

[32] S.D. Pandey, V.K. Nema, Experimental analysis of heat transfer and friction factor of nanofluid as a coolant in a corrugated plate heat exchanger, Exp. Therm. Fluid Sci. 38 (2012) 248-256.

[33] A.K. Tiwari, P. Ghosh, J. Sarkar, Heat transfer and pressure drop characteristics of $\mathrm{CeO}_{2} /$ water nanofluid in plate heat exchanger, Appl. Therm. Eng. 57 (1-2) (2013) 24-32. 